\title{
Social Network and Organizational Leadership at the Higher Education Institution: A Case Study
}

\section{Gugyh Susandy* 이 | Yanu Endar Prasetyo² ${ }^{\circ}$}

'Sekolah Tinggi Ilmu Ekonomi Sutaatmadja, Department of Management, Subang, Indonesia ${ }^{2}$ Lembaga Ilmu Pengetahuan Indonesia, Jakarta, Indonesia

*Correspondence to: Gugyh Susandy, Sekolah Tinggi Ilmu Ekonomi Sutaatmadja, Department of Management, Jl. Otto Iskandardinata No. 76 Subang 41211, Indonesia. E-mail: gghsusandy99@gmail.com

\begin{abstract}
The roles of social network and informal leadership network are not only crucial to companies or government institutions, but also to the academic institutions. As the interaction within the organization becomes more complex and dynamic, there is a lack of knowledge of the overall picture of informal leadership network at the higher education institution. In this study, we conducted a comprehensive analysis of three types of social networks and informal leadership in Sekolah Tinggi Ilmu Ekonomi Sutaatmadja (STIESA). They are the information network in an internal organization, cooperation network in technical problem solving of the organization, and a personal support network in the organization. The method used in this research was survey and Social Network Analysis (SNA). The respondents in this research were the whole leaders and staffs of STIESA. The findings of this study classified the three social networks and informal leadership and built network matric to be further explored for the strategic decision-making process of the organization. Each type of social network and informal leadership, along with its characteristics, is discussed and explored.
\end{abstract}

Keywords: informal leadership network, social network.

Article info: Received 28 September 2018 | revised 17 December 2018 | accepted 25 January 2019

Recommended citation: Susandy, G., \& Prasetyo, Y. E. (2019). Social Network and Organizational Leadership at the Higher Education Institution: A Case Study. Indonesian Journal of Sustainability Accounting and Management, 3(1), 37-48. https://doi.org/10.28992/ijsam.v3i1.70.

\section{INTRODUCTION}

A leadership network is a response to a rapidly changing and increasingly disrupted world, requiring the policyholders to have the ability to collaborate and solve complex problems faster. Leadership network is the ability of leaders to manage resources and support the running of an organization, whether individually or collectively. The vital role of this leadership network is not only applicable to corporations or government institutions but also to the academic world such as universities or higher education institutions whose challenges and dynamics become more complicated and convoluted.

Most of the campus managers, both leaders, and staff, are people with a high education background and have above average intellectual abilities. However, it has been the challenge of whether a group of people with a higher education background can grow and move collectively or tend to be individualistic and isolated. 
Unfortunately, the campus management structure is relatively slow in responding to external and internal changes, where the existing structure is relatively rigid and unchanged over the years. Unlike public organizations, private organizations such as business institutions are more responsive in dealing with change. It is not always that every move should automatically be responded immediately, but specific and essential modifications require the organizations respond quickly because the change will affect the organization in the long term.

Unlike the state-owned campus, the private campus or college in Indonesia is unique in its organizational structure where the management is organized by a legal body of foundation. Foundation is funded mostly by individuals and families. It is possible that a higher education institution contains people who still have a family relationship. Of course, there is a management system that separates the conflict of interest of the foundation with the higher education implementing unit. With this uniqueness, the social networking and proper leadership are needed by private campus to accumulate resources and opportunities to be a power factor in the direction of excellence, not to be the weakness.

Based on the context and background of the private college management, this study analyzes three types of social and informal leadership networks within the internal environment of the organization, especially in Sekolah Tinggi Ilmu Ekonomi Sutaatmadja (STIESA), Subang, West Java. The three forms of social and informal leadership networks are indicated by: 1) information network, 2) cooperation network, and 3) personal support network. Social Network Analysis (SNA) was used as a tool to raise awareness of STIESA leaders about the power of the networks and encourage more significant expansion of the connection and network capacity to collaborate. We focused on understanding and measuring the differences in these social and informal leadership networks at STIESA. Our analysis starts by classifying those three different networks and then showing the network metrics which can be explored further for strategic and organizational decision making. Each social network is portrayed along with its respective characteristics and quantitative values of the network.

Leadership is one of the most widely studied fields in the management science because it plays a significant role in knowledge processes such as sharing, creating, and the implementing successful knowledge management efforts (von Krogh et al., 2012). In this article, we shed new light on the relationships among the organizational contexts or structures and the informal collegial networks (interactions) of the faculties (lectures and staff) of a private college. It is essential to not only focus on how others see and evaluate leaders but also how to identify the leaders and followers within the organization (leadership and followership) itself. Understanding how leaders and followers see and define themselves in complex interactions is an important piece of the leadership study which can offer unique insight on the leadership processes and evaluation (Epitropaki et al., 2016).

The formal structure in most organizations provides limited contact opportunities among members of different workgroups. Groups in one part of the firm are often unaware of the resources and ideas in other groups. Because information tends to circulate more readily inside, organizational groups develop distinctive perspectives and skills. People in different groups participate in different social worlds; they "circulate in different flows of information" (Burt, 2000). A crucial task of the group leader is to serve as a bridge between formal organizational groups (Burt, 2000), thereby serving as a conduit to useful information and knowledge located outside the group (e.g., Kotter, 2001). Field-based studies have shown that leaders devote considerable time to these activities (e.g., Mintzberg, 1973). Leaders rely on their interpersonal ties outside the group as a tool for gathering and analyzing information: the social network of the leader can be thought of as "an army of people processing information" that can call the leader's attention to emerging opportunities and impending threats (Burt et al., 2013). 
Our study focuses directly on the personal bond of friendship developing between the leaders within organizational groups. We emphasize personal network and friendship relations because they can be important especially for getting things done in organizations (e.g., Ibarra, 1993). For groups engaged in complex organizational tasks, much of the information that can give the group a performance edge over other groups tends to be of a tacit nature. A study found that strong friendship ties are especially good conduits for the flow of tacit information (Hansen, 1999). Group leaders who are friends are more likely to go beyond the formal job requirements to help each other improve group performance (Mehra et al., 2006).

\section{METHODS}

Social Network Analysis (SNA) is concerned with the interpersonal interactions that constitute to the social structure of a group (Friedkin \& Slater, 1994). Two features of social networks in the higher education appear especially relevant to the leader's centrality in the institutions, the communication network, and the cohesion of this network. SNA can be used for evaluating leadership networks and articulating many concepts such as power, influence, cliques, and others (Bandyopadhyay et al., 2011). It is a valuable tool for indicating the communication barriers within an organization. What makes social network analysis unique is the capacity to visualize a system of relationships otherwise would be hidden from view (Prasetyo, 2017). Personal and organizational networks measure two fundamental questions related to the communication network and friendship network (Zohar \& Tenne-Gazit, 2008). We used Qualtrics for data collection, sent the questionnaire to all the members of the organization ( $N=28$ respondents), and visualized the results using Node $\mathrm{XL}$ Pro software (Hansen et al., 2011). Since numbers of the population and the network are small, the sampling was not necessary (Robins, 2015). In this study, we ask several main questions as shown in Table 1.

\section{Table 1 Questions for the SNA Survey}

\begin{tabular}{ll}
\hline No. & \multicolumn{1}{c}{ Questions } \\
\hline 1. & How long have you been working at STIESA? \\
2. In the past month, which of the names below exchanged work-related information with you at the campus? \\
3. In the last month, which of the names below helped you solve technical problems in your work at the campus? \\
4. In the last six months, which of the names below provided support or advice related to your personal issues at \\
the campus? \\
5. How often do you receive information about your work from the following colleagues? \\
7. How often do you discuss technical issues related to your work with the following colleagues? \\
7. How often do you discuss your difficult personal issues with the following colleagues? \\
8. In the past month, with whom have you spent your time relaxing outside of office hours/outside campus \\
\hline
\end{tabular}

\section{RESULTS AND DISCUSSION}

Every form of organization is a network. However, when considered as a form of governance, the network form can be distinctly characterized. Hierarchy is one of the organizational forms that can be represented with the basic social network analysis (Mones et al., 2012). Podolny \& Page (1998) argued that organization network is any collection of actors who pursue goals and exchange relations with one another and at the same time. There is a lack of legitimate organizational authority to arbitrate and resolve disputes that may arise during the exchange. 
Furthermore, sociologists argued that network forms of organization could not be considered hierarchies; instead, network forms of the organization represented a unique alternative possessing its logic (Powell, 1990) and had many distinct efficiency advantages not possessed by simple hierarchies. In another hand, technology has reorganized how we live, how we communicate, and how we learn in an organization. The organization and the individual are both learning organisms, and the learning process should be reflective and connected with the underlying social environments. Connections between ideas and fields can create innovations within the organization. Connectivism presents a model of learning that acknowledges the paradigm shifts in our society where learning is no longer an individualistic activity. For this reason, we investigated the connection between members (faculty and staff) in the specific work environment (higher education institution, STIESA) represented by the three networks of the internal organization, namely information network, cooperation network, and personal support.

\section{Information Network}

ADS is the head of academic administration (Head of BAA) who has a central function as a data center and academic services for students and lecturers. From the results of social network analysis, it is appropriate that ADS become the center of the information network. Furthermore, GS is the first chairman assistant of academic and student affairs who must assist the chairman of STIESA in making the policies of academic and student affairs. ADS is responsible at the level of execution, while GS is responsible at the policy level. The position of $G S$ as the second center in the information network is in accordance with the proper role and function of the organization.

AK is the head of the accounting department who has the task and function for assisting GS in achieving the "Tri Dharma Perguruan Tinggi" program, especially in research activities, community services, lecturers training, and curriculum development of the accounting department. The informal position of AK is on track, but the location of BA who is the head of the management department should not be far from AK as the third network center. BA, having family ties with the founder of the institute, has a closed position to the position of chairman of the foundation (see Figure 1).

$M M$ is the head of the library who has the primary task and function as a center for learning resources for students, lecturers, and library visitors. MM position in the network is right, that is the fourth center in the information network. Another information network center is SM serving as the head of quality assurance agency (Head of BPM) with the task of assisting the chairman of STIESA in monitoring and evaluating all parts of STIESA organizational structure. Furthermore, the sixth important person in the information network is IU who is the chairman assistant of the financial and general administration (second chairman assistant). Her function is to assist the chairman of STIESA in implementing the primary goals of education, research and community services. Thus, the position of IU is adjacent to GS (first chairman assistant).

By using social network analysis, three clusters of information networks were formed on the organizational structure and informal leadership of STIESA. The first part is the cluster with the lowest density of 0.603 (Figure 2). There are 13 people in this first cluster of the information network, centered on the ADS. Members of the cluster network are permanent lecturers of management department ( 6 persons), permanent lecturer of accounting department (1 person), student affairs colleagues ( 2 persons), academic staff, library staff, and information system staff ( 3 persons). When compared with the formal structure and rules, it can be seen that the head of academic, head of student affairs and head of the library are already right being in the same cluster because they have similar task and service area. Another finding in this first cluster is the position of the head of the information system which is in the different group. 


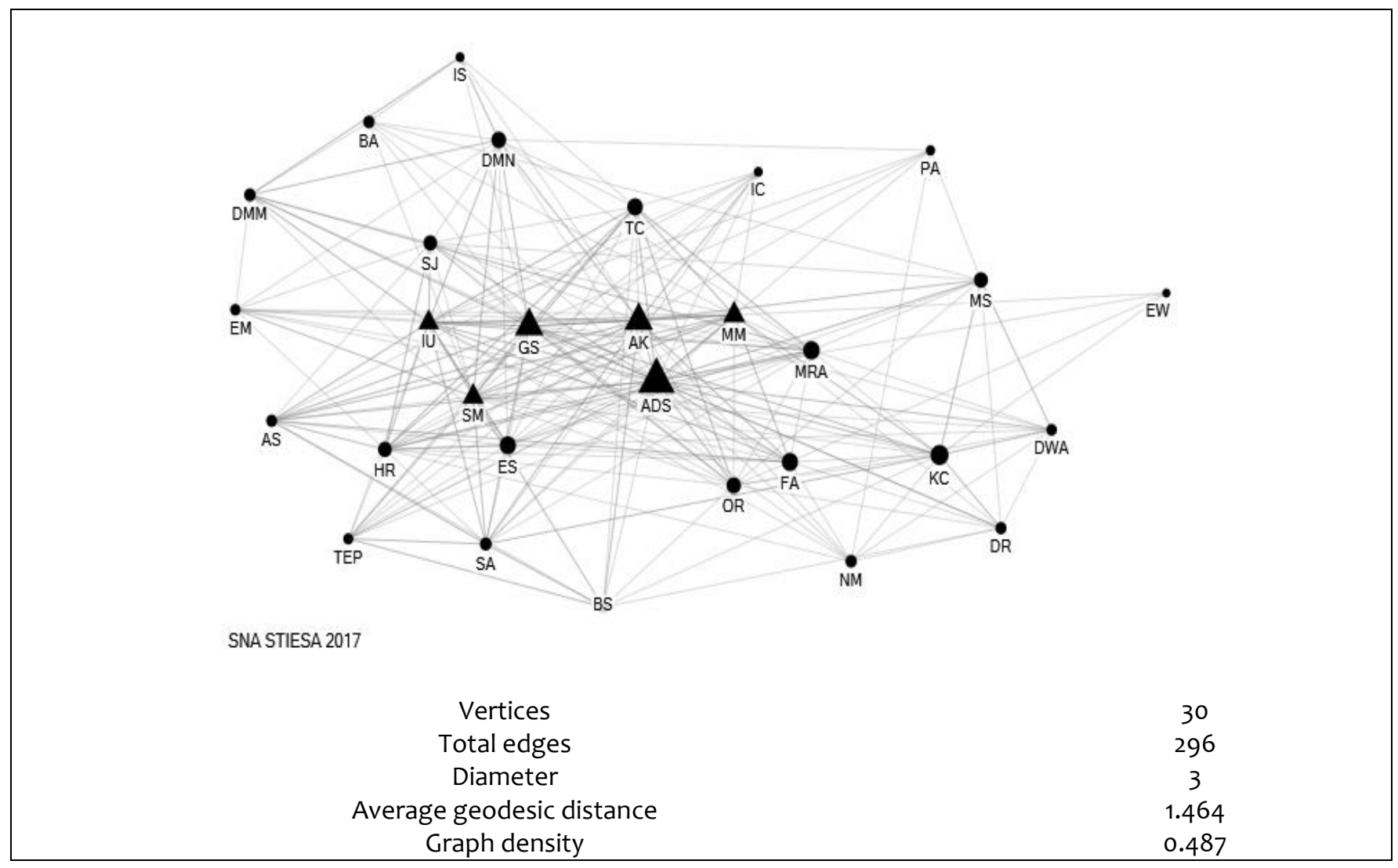

Figure 1 Exchanging Information between Respondents in the Last One Month. Vertex Shape and Size: Betweenness Centrality (Edge Opacity 50\%)

The second group is cluster two with the highest information density of 0.867 (Figure 2). The number of people in this cluster amounted to 10 people and centered on AK. Members of this cluster network are the permanent lecturers of accounting department ( 3 persons), heads of finance and information system ( 2 persons), the staff of finance (2 persons), the second chairman assistant, and head of BPM. Compared to the formal task and function, it can be seen that the financial department and head of SI are right in this second cluster because they serve as the supporting team. Another finding is that the second chairman assistant and head of BPM are adjacent to AK. IU and SM are permanent lecturers of the accounting department as well. Indeed, their positions should be structurally more appropriate with the first chairman assistant and chairman. Furthermore, the head of finance is right along with his staff in this second cluster. AK's staff are also right in the same group together with the head of the accounting department.

The third group is cluster three with the second highest information density of 0.810 (Figure 2). There are seven people in this cluster centered on GS. The members of this third cluster are the chairman of Sutaatmadja foundation, chairman of STIESA, head of the general division, head of the management department and staff of BPM. Compared to his primary duties and functions, it can be seen that the first chairman assistant has already right position together with the chairman of STIESA. As the chairman STIESA also serves at a state institution in Jakarta, the first chairman assistant becomes the liaison with the foundation.

Moreover, the position of head of the general division in this cluster is quite interesting, grouped with the head of the management department and staff of BPM. This is caused by the family relationship between them so it may affect their positions in the group as well. In addition to family proximity factors, it can be seen 
that the head of the general division is given the mandate to make a decision, both on behalf of STIESA and Sutaatmadja foundation.

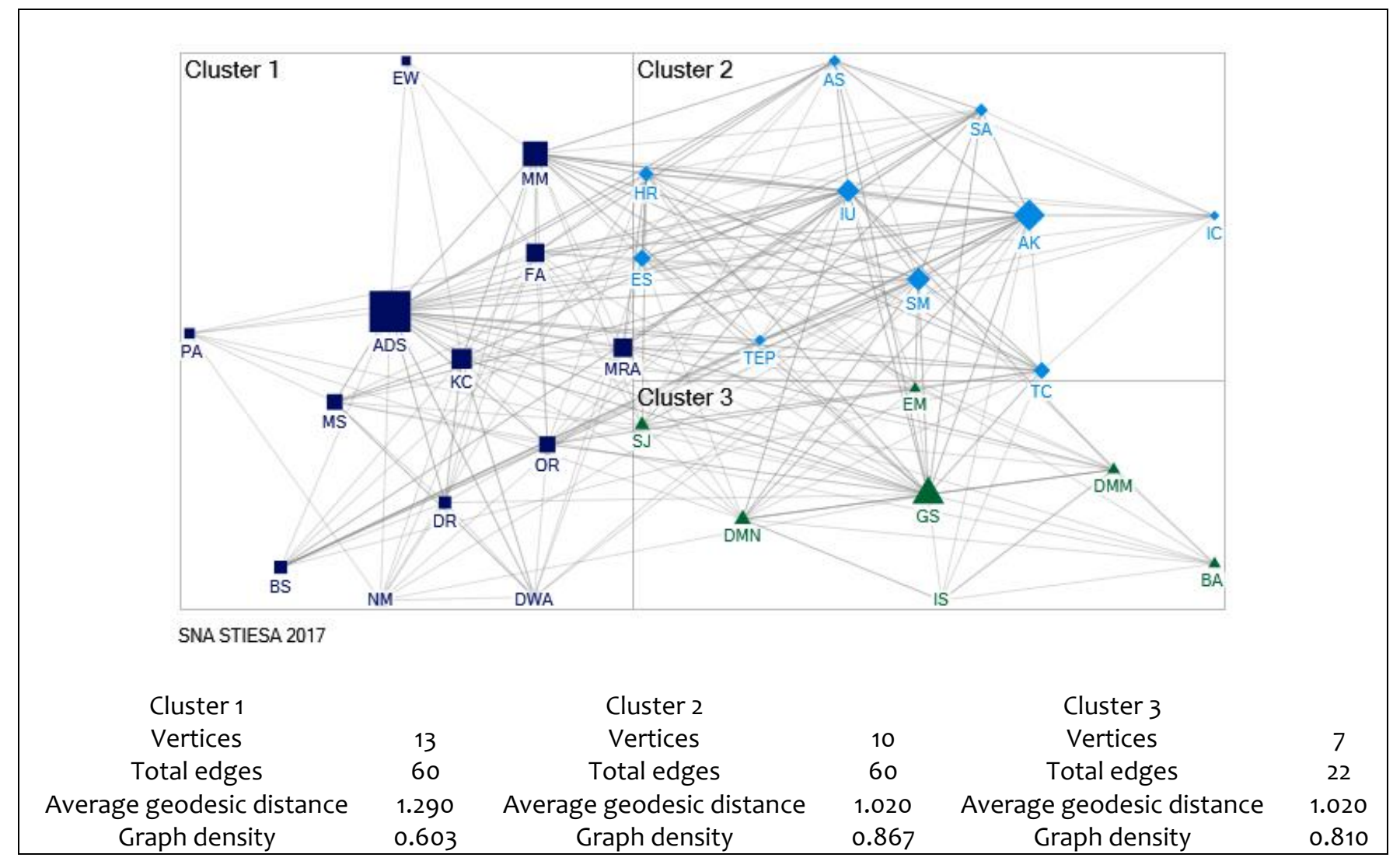

Figure 2 A Cluster of Information Exchange between Respondents in the Last One Month. Vertex Shape and Size: Betweenness Centrality (Edge Opacity 30\%)

\section{Cooperation Network}

There are three different types of relationships, namely prescribed relationship (determined by external bodies such as management), instrumental relationship (dealing with purposes and goals) and expressive relationship (focusing on emotional aspects) (Ibarra, 1993). In this research, we studied the network of 'who communicates with whom' that will make an information flow makes sense within the organization (Robins, 2015). This is because people can dislike one another or find themselves challenging to work together. In term of solving technical problems, our network is centered on ADS, AK, MS (chairman of COE POM), DMN (chairman of STIESA), DMM (secretary of foundation), GS (first chairman assistant), ES (head of finance), TC (head of IT), and SJ (head of general division). This finding shows the function of decision making according to the primary task and function. The chairman is still involved in the technical solution because of the three reasons, namely resources, time and budget, remaining as his authority. The involvement of the secretary of the foundation in technical policy is because the decisions on investment and asset maintenance are within the authority of the foundation. 


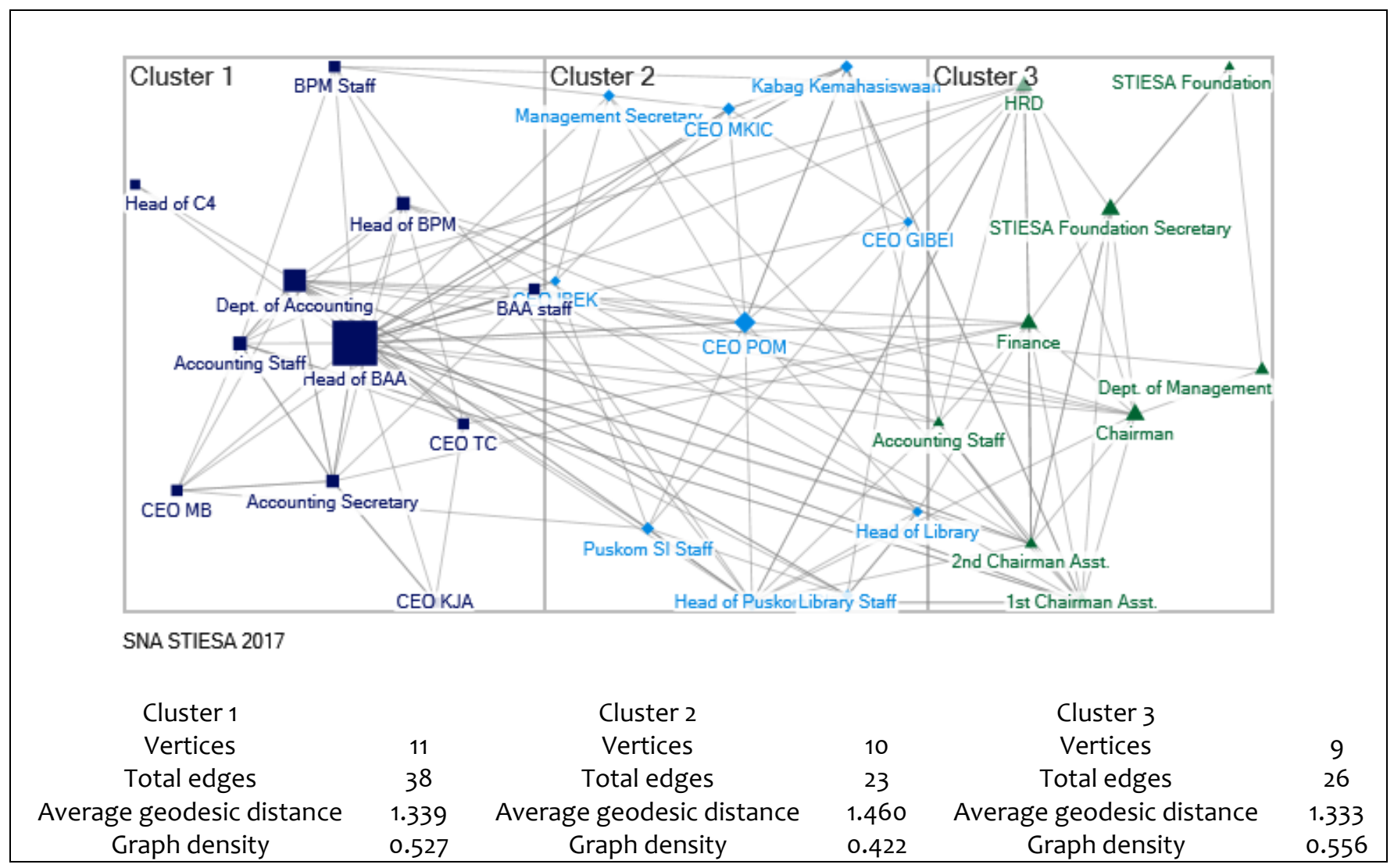

Figure 3 Who Helped You Solve Technical Problems in the Last Month? Vertex Shape and Size: Betweenness Centrality (Edge Opacity 30\%)

We found three clusters of cooperation networks in organizational structure and informal leadership at STIESA. The first cluster is the group with the second highest density of 0.527 (Figure 3). Compared to the information network, the density of the cooperation network is relatively lower. There are eleven people in the first cluster of the cooperation network centered on the head of academic administration. The network members in this cluster are different from the members of the information network, even the head of the accounting department and head of BPM are grouped with the head of academic administration. These findings indicate that the decision-making process in the technical problem level does have a different relationship with an information network.

The second cluster has the lowest density of 0.422 (Figure 3). Compared with the density of the information network, the cooperation network density is relatively lower. There are ten people in the second cluster centered on the head of COE POM. This finding is quite interesting because the COE is a unique institution engaged in the learning process of operational management. The third cluster in this network has the highest density of 0.556 (Figure 3). Compared to the density of the information network, the cooperation network is still lower. There are nine people in the third cluster centered on DMN. According to the main task and function of the organization, it can be seen that the first chairman assistant and the second chairman assistant are right along with the chairman of STIESA in this group. Head of finance and the staff are also part of this network as the issues of budget policy should be under the coordination and control of the chairman. 


\section{Personal Support}

Impersonality is a characteristic of the formal-bureaucratic model. In this model, personal emotions and relationships between people are to be role-based, segmental, and instrumental. Collectivist organizations, on the other hand, strive toward the ideal of community where the relationships between members are to be holistic, affective, and of value in themselves (Rothschild-Whitt, 1979). Regarding personal support within the collective organizations, the respondents in our research indicated that the ones who provided personal support the most to other members were IU, ADS, SM, MS, AK, FA, GS, HR, KC, and ES. The map has shown that the functionality of the personal support is not as robust as the information network and cooperation networks. The value of a personal support network is still below the previous two networks. However, on the other hand, there is an informal support network with perfect density or clique with a value of 1 (cluster 4: IU, GS, DMM, IS, DMN).

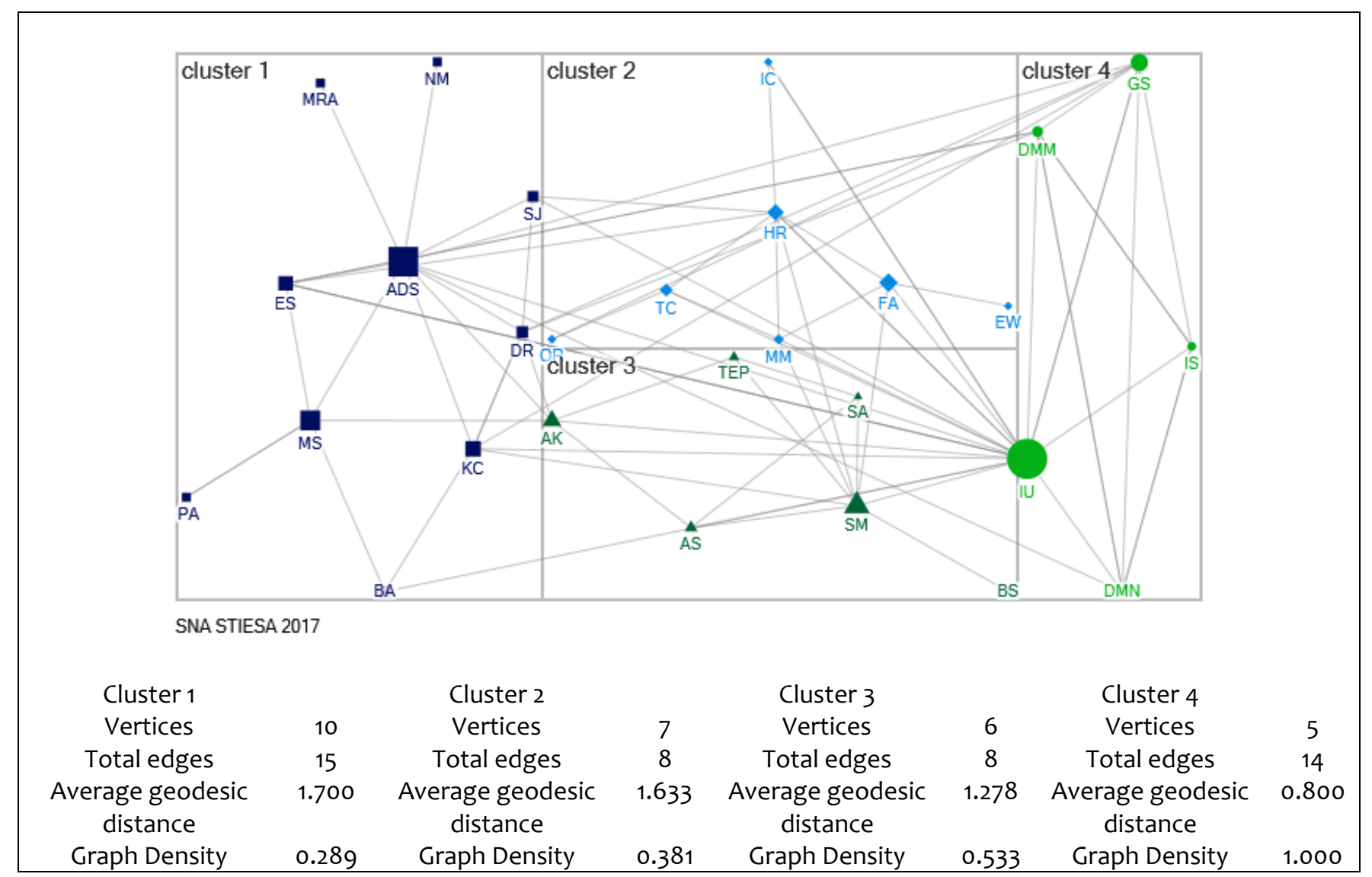

\section{Figure 4 Provision of Personal Support for Each Other in the Past Month. Vertex Shape and Size: Betweenness Centrality (Edge Opacity 30\%)}

Social network analysis found four clusters of personal support networks within the informal organizational leadership at STIESA. The first cluster has the lowest density of 0.289 (Figure 4). Compared to the density in the information networks and cooperation networks, the personal support network is relatively lower. Ten people are in the personal support network of the first cluster centered on ADS. The members in this cluster are different from previous networks. Head of the management department who is usually in the third cluster, in this personal support is in the first cluster. Similarly, the head of the general division and head 
of finance are also in this first cluster. BA, who has been in a network with IS and has a family relationship, does not have a different bond in this personal support network.

The second cluster has the second lowest density of 0.381 (Figure 4). Compared to the density of information network and cooperation networks, the personal support network is relatively lower. There are seven people in the personal support network centered on the FA. FA's position is interesting because FA is also the treasurer of the STIESA Fund. So, structurally, FA has helped many people in the whole network. There are two divisions with their staff who have a personal support network in this second cluster, namely IT and Library division. The third cluster is the group with the second highest density of 0.533 (Figure 4). There are six people in the third cluster of personal support network centered on SM. In this cluster, the lecturers of the accounting department are quite dominant.

The fourth cluster has the highest density and even reaches the clique point. There are five people centered on IU. The members of this fourth cluster turn out to be the same as members of the cooperation network. There are strong chemistry and personal relationship between the chairman of STIESA and his closest assistants. This relationship is vital for the creation of harmonization supporting the performance of the organization.

\section{Dealing with the Complex Personal Issues}

Discussing complicated personal issues with colleagues is one of the indicators to see the closeness and openness among members of an organization. This closeness can have a good or bad impact on the organization's performance. The frequencies of talking about complex individual problems among STIESA members indicate that their intensity to talking about the personal issue is quite diverse, ranging from every day to one to two times a year. We can see from the diagram (Figure 5) that most of the members talk about their personal problem once a month, one to two times a year, one to two times a week and only a few members talk about it every day. There seems to be no single factor that is dominant in determining the intensity of personal problem communication among the members of the organization.

The exchange of complex personal problems within an organization can be viewed positively or negatively. In the positive side, it can be stated that the atmosphere and work environment provide comfort and secure feelings to each person in expressing feelings openly, even the quite personal things. Conversely, the more personal working environment can lead to a higher frequency of interpersonal conflict and can interfere with the productivity of personal and collective work. The result of the frequency mapping of personal problems among members of STIESA shows the low exchange of daily personal problems on campus. However, this low exchange seems to be caused by the limited interaction among the members because many lecturers have a residence outside the city.

The informal relationships between members and leaders in the organization can also be seen from how often they spend time outside office hours. Our map shows the results of how the member spend their leisure time together. We can see that 13 people often spend time together outside of working hours, namely DR, BS, MS, NM, ADS, ES, TC, GS, DMM, MRA, OR and EM. The people interacting outside the office the most are DR, $\mathrm{OR}, \mathrm{ADS}$, and BS (see Figure 6). Those persons (in blue nodes) will quickly channel and spread various information to the entire network, whether essential or not. 


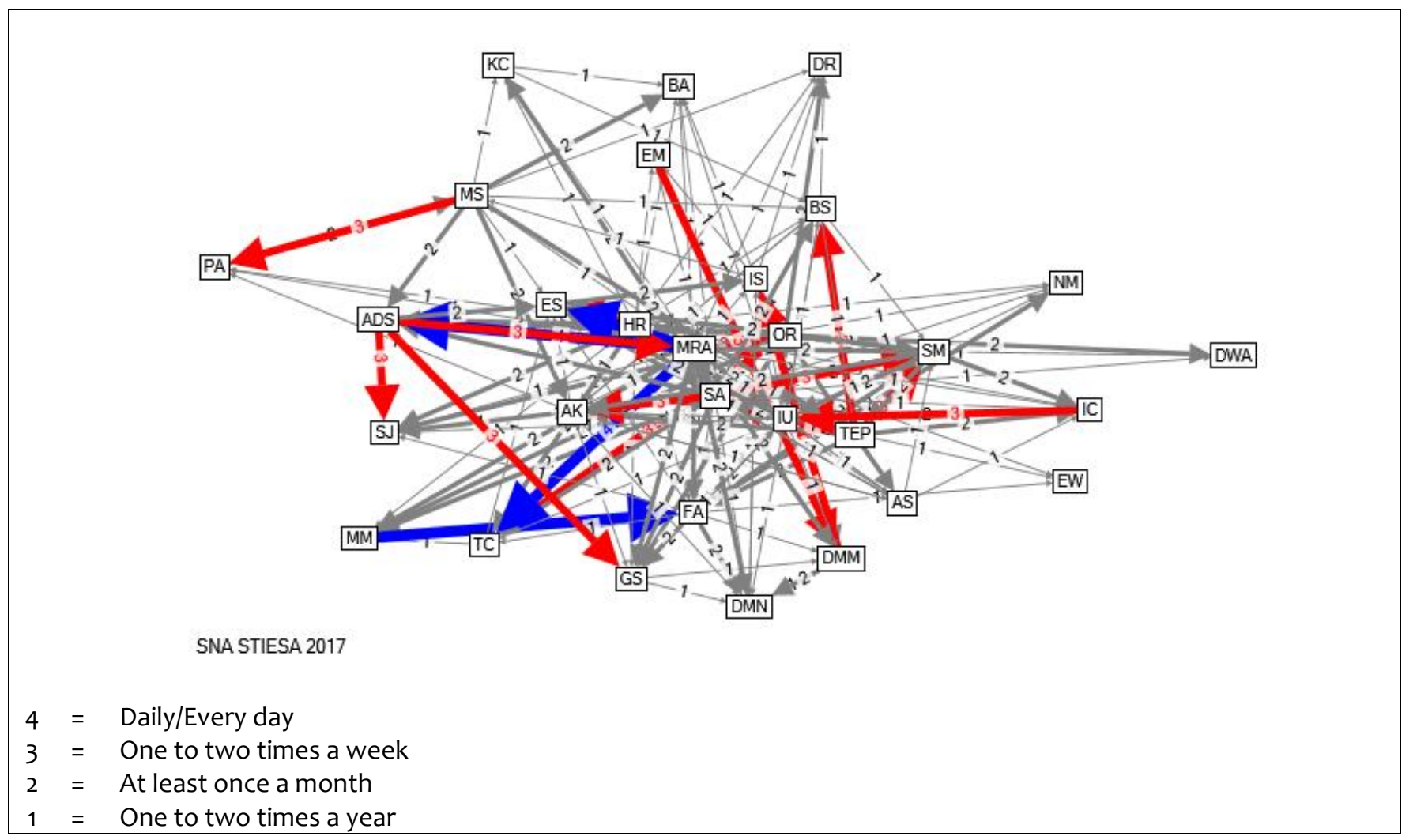

Figure 5 Discussing Complex Personal Issues among Members

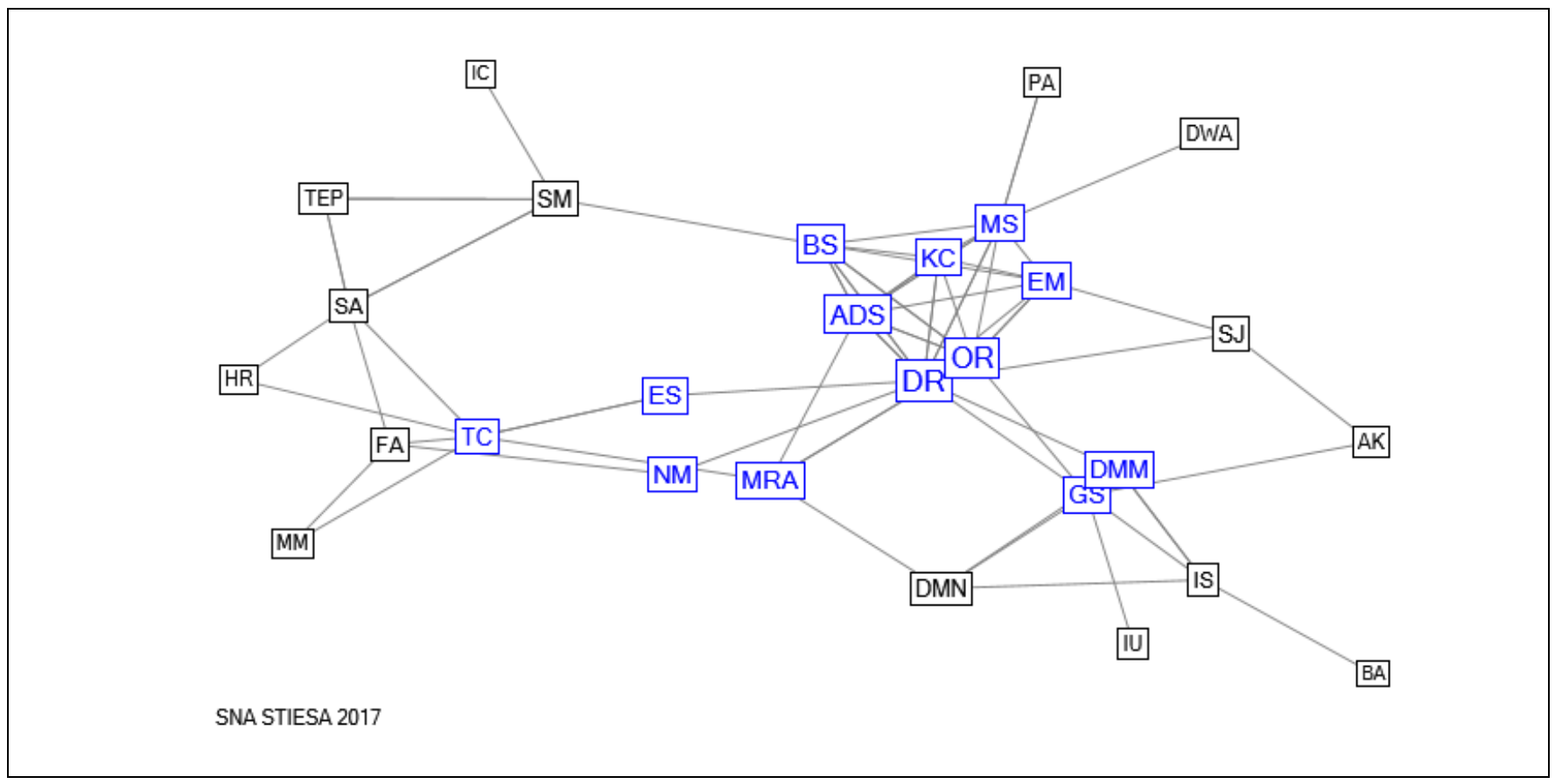

Figure 6 Spending Leisure Time outside the Campus. Closeness Centrality (Blue $>15$ ). Information Derived from the Blue Color Will Spread Faster Throughout the Network 


\section{CONCLUSION}

This study visualizes social network and informal organizational leadership through three types of networks, namely information network, cooperation network, and personal support network in a private college organization. Information network analysis focuses on ADS as the head of academic administration and GS as the first chairman assistant of academic and student affairs. Network information forms three clusters with network density ranging from 0.6 to 0.8 (the networks are good but still need improvement). The best cluster is the second level network (middle-level management), while the members of each cluster of information network are quite varied, depending on the structure or field of work.

Concerning the technical problem solving of daily work, the network is centered on ADS as the head of academic administration and $A K$ as the head of the accounting department. This situation shows the right combination of the technical learning problem which is centered on ADS and the lecturer's technical problems in research and community service which is centered on AK. This network of technical problem-solving forms three clusters. Network density ranges from 0.4 to 0.5 (low score and needs improvement). The best cluster in the third cluster (top level management) and the members in each cluster of the technical problem-solving network are not only determined by one factor of structure or field of work of the parties, but also by other factors such as the relationship between members.

A personal support network is centered on ADS as the head of academic administration and IU as the second chairman assistant. Personal support network forms 4 clusters with the network density ranging from 0.2 to 1 . This density variation means that the bonds within these three clusters still vary from lowest to the most robust. The best cluster in the fourth cluster (top level management) and the members of the personal support network are influenced by many factors such as gender equality, intimate closeness, and work similarity. However, in the fourth cluster, the best factor forming the cluster is merely the similarity of the managerial level.

The network analysis of the members discussing the complex personal problems forms four groups, namely, those who talk about personal issues daily, one to two times a week, once a month, and one to two times a year. The most dominant one is once a month, while the lowest is every day. No single factor is dominant in determining the intensity of personal communication. It is, however, a combination of gender, occupation, family relationship, and other hidden subjective factors. Regarding the time spent together outside of working hours, there are 13 people in the center of this network. In this network, the delivery of information across the network or to other members is the fastest.

Based on the results of social network analysis and leader network of this study, it can be concluded that STIESA organizational structure is run with a mixed leadership pattern between professional and familial patterns. The improvement efforts are needed, namely: 1) increasing the quality and intensity of communication and dissemination of information within the internal organization to be faster and more transparent, 2) strengthening social networking and internal leadership, and 3) building roadmaps for enhancing external networks based on internal strength and other criteria according to mission and organizational interests.

\section{ORCID}

Gugyh Susandy (ID https://orcid.org/0000-0003-1273-5488

Yanu Endar Prasetyo (1) https://orcid.org/0000-0003-3382-1131 


\section{REFERENCES}

Bandyopadhyay, S., Rao, A. R., \& Sinha, B. K. (2011). Models for Social Networks with Statistical Applications. Thousand Oaks California: SAGE Publications, Inc. https://doi.org/10.4135/9781452226538

Burt, R. S. (2000). The Network Structure of Social Capital. In B. M. Staw \& R. I. Sutton (Eds.), Research in Organizational Behavior (Vol. 22, pp. 345-423). Elsevier Science Inc. https://doi.org/10.1016/S01913085(00)22009-1

Burt, R. S., Kilduff, M., \& Tasselli, S. (2013). Social Network Analysis: Foundations and Frontiers on Advantage. Annual Review of Psychology, 64(1), 527-547. https://doi.org/10.1146/annurev-psych-113011-143828

Epitropaki, O., Kapoutsis, I., Ellen, B. P., Ferris, G. R., Drivas, K., \& Ntotsi, A. (2016). Navigating Uneven Terrain: The Roles of Political Skill and LMX Differentiation in Prediction of Work Relationship Quality and Work Outcomes. Journal of Organizational Behavior, 37(7), 1078-1103. https://doi.org/10.1002/job.2100

Friedkin, N. E., \& Slater, M. R. (1994). School Leadership and Performance: A Social Network Approach. Sociology of Education, 67(2), 139-157. https://doi.org/10.2307/2112701

Hansen, D. L., Shneiderman, B., \& Smith, M. A. (2011). Analyzing Social Media Networks with NodeXL: Insights from a Connected World. Elsevier. https://doi.org/10.1016/C2009-0-64028-9

Hansen, M. T. (1999). The Search-Transfer Problem: The Role of Weak Ties in Sharing Knowledge across Organization Subunits. Administrative Science Quarterly, 44(1), 82. https://doi.org/10.2307/2667032

Ibarra, H. (1993). Personal Networks of Women and Minorities in Management: A Conceptual Framework. Academy of Management Review, 18(1), 56-87. https://doi.org/10.5465/amr.1993.3997507

Kotter, J. P. (2001). What Leaders Really Do. Harvard Business Review.

Mehra, A., Dixon, A. L., Brass, D. J., \& Robertson, B. (2006). The Social Network Ties of Group Leaders: Implications for Group Performance and Leader Reputation. Organization Science, 17(1), 64-79. https://doi.org/10.1287/orsc.1050.0158

Mintzberg, H. (1973). The Nature of Managerial Work. New York: Harper and Row.

Mones, E., Vicsek, L., \& Vicsek, T. (2012). Hierarchy Measure for Complex Networks. PLoS ONE, 7(3), e33799. https://doi.org/10.1371/journal.pone.0033799

Podolny, J. M., \& Page, K. L. (1998). Network Forms of Organization. Annual Review of Sociology, 24(1), 57-76. https://doi.org/10.1146/annurev.soc.24.1.57

Powell, W. W. (1990). Neither Market nor Hierarchy: Network Forms of Organization. In B. M. Staw \& L. L. Cummings (Eds.), Research in Organizational Behavior (pp. 295-336). JAI Press Inc.

Prasetyo, Y. E. (2017). Mapping and Exploring Informal Network in Organizational and Community Leadership. Journal of Asian Rural Studies, 2(1), 37-48.

Robins, G. (2015). Doing Social Network Research: Network-based Research Design for Social Scientists. SAGE Publications Ltd.

Rothschild-Whitt, J. (1979). The Collectivist Organization: An Alternative to Rational-Bureaucratic Models. American Sociological Review, 44(4), 509-527.

von Krogh, G., Nonaka, I., \& Rechsteiner, L. (2012). Leadership in Organizational Knowledge Creation: A Review and Framework. Journal of Management Studies, 49(1), 240-277. https://doi.org/10.1111/j.14676486.2010.00978.x

Zohar, D., \& Tenne-Gazit, O. (2008). Transformational Leadership and Group Interaction as Climate Antecedents: A Social Network Analysis. Journal of Applied Psychology, 93(4), 744-757. https://doi.org/10.1037/0021-9010.93.4.744 